\title{
Multiobjective Optimal Placement of Public Fast Charging Station on Power Distribution Network Using Hybrid Ant Colony Optimization and Bees Algorithm
}

\author{
Prakornchai Phonrattanasak $^{\# 1}$, Nopbhorn Leeprechanon ${ }^{* 2}$ \\ \# Department of Electrical Engineering, North Eastern University, \\ 199/19 Mitraparp road, Khonkaen, Thailand \\ ${ }^{1}$ tumneu@hotmail.com \\ ${ }^{*}$ Department of Electrical and Computer Engineering, Thammasat University \\ 99 Moo 18, PhahonYothin Road, Khlong Nueng, Khlong Luang, Pathumthani,Thailand \\ 2 nopbhorn@engr.tu.ac.th
}

Abstract-The multiobjective hybrid ant colony optimization (ACO) and bees algorithm (BA) is proposed to solve multiobjective optimal placement of public fast charging station (FCS) for battery electric vehicle (BEV) on power distribution system. This new algorithm is named as MOHACOBA. It is used to minimize simultaneously both total cost associated with FCS and feeder loss on distribution network under many constraints of the power distribution system and traffic condition. The IEEE-69-bus in Tianjin Development Zone is the test system for the proposed approach with three case studies on fast charging head size. In order to verify performance of algorithm, four performance metrics (Hypervolume ratio, error ratio, spread and epsilon indicator) is applied to measure quality of Pareto optimal front of proposed method and it is compared with other multiobjective optimization methods i.e. MOPSO, NSGA II and MOACO. From the results, quality of Pareto optimal front of proposed approach is better than other methods. It can be summarized that MOHACOBA algorithm has effectiveness and robustness to obtain multiobjective optimal placement of FCS on power distribution system.

Keyword-Fast charging station, Battery electric vehicle, Ant colony optimization, Bees algorithm, Power distribution system

\begin{tabular}{|c|c|c|c|}
\hline$n_{\mathrm{FCS}}$ & Number of fast charging stations & $N_{\mathrm{S}}$ & $\begin{array}{l}\text { Number of branches in the power } \\
\text { distribution system }\end{array}$ \\
\hline$n_{\mathrm{EV}}$ & $\begin{array}{l}\text { Total number of BEVs to be } \\
\text { charged per day }\end{array}$ & $D^{\max }$ & $\begin{array}{l}\text { Maximum limit of distance between the } \\
\text { FCS and the EV load point (meter) }\end{array}$ \\
\hline$n_{\mathrm{EV} p}$ & $\begin{array}{l}\text { Number of BEVs in the } p^{\text {th }} \mathrm{EV} \\
\text { load point }\end{array}$ & $D_{\mathrm{FCS}}$ & $\begin{array}{l}\text { Distance between two adjacent FCSs } \\
\text { (meter) }\end{array}$ \\
\hline$t_{\mathrm{CHG}}$ & $\begin{array}{l}\text { Average charge time of an BEV } \\
\text { (hr) }\end{array}$ & $D_{\mathrm{FCS}}^{\min }$ & $\begin{array}{l}\text { Minimum distance limit of two adjacent } \\
\text { FCSs (meter) }\end{array}$ \\
\hline$t_{\mathrm{s}}$ & $\begin{array}{l}\text { Service hours of FCS each day } \\
\text { (hr) }\end{array}$ & $D_{\mathrm{FCS}}^{\max }$ & $\begin{array}{l}\text { Maximum distance limit of two adjacent } \\
\text { FCSs (meter) }\end{array}$ \\
\hline$q_{\mathrm{H}}$ & $\begin{array}{l}\text { Number of fast charger head in a } \\
\text { FCS }\end{array}$ & $l_{\mathrm{F}}$ & Load factor of FCSs \\
\hline ceiling [ & Ceiling function & $P_{\mathrm{FCS} i}^{\text {output }}$ & $\begin{array}{l}\text { Rated power output of a FCS at the } i^{\text {th }} \text { bus } \\
(\mathrm{kW})\end{array}$ \\
\hline rand [ ] & Random function & $P_{\mathrm{FCS} i}^{\text {input }}$ & $\begin{array}{l}\text { Active power input of a FCS at the } i^{\text {th }} \text { bus } \\
(\mathrm{kW})\end{array}$ \\
\hline Cost & $\begin{array}{l}\text { Total cost associated with FCS } \\
\text { (CNY) }\end{array}$ & $Q_{\mathrm{FCS} i}^{\text {input }}$ & $\begin{array}{l}\text { Reactive power input of a FCS at the } i^{\text {th }} \\
\text { bus (kVar) }\end{array}$ \\
\hline$C_{\mathrm{INV}}$ & $\begin{array}{l}\text { Initial investment cost of FCSs } \\
\text { (CNY) }\end{array}$ & $S_{\mathrm{FCS} i}^{\text {input }}$ & $\begin{array}{l}\text { Apparent power input of a FCS at the } i^{\text {th }} \\
\text { bus (kVA) }\end{array}$ \\
\hline
\end{tabular}




\begin{tabular}{|c|c|c|c|}
\hline$C_{\mathrm{O} \& \mathrm{M}}$ & $\begin{array}{l}\text { Annual operating and } \\
\text { maintenance cost of FCSs } \\
(\mathrm{CNY})\end{array}$ & $P_{\mathrm{Hi}}^{\text {output }}$ & $\begin{array}{l}\text { Rated power output of fast charging head } \\
\text { of a FCS at the } i^{\text {th }} \text { bus (kW) }\end{array}$ \\
\hline$C_{\mathrm{TRV}}$ & $\begin{array}{l}\text { Annual travelling cost of all } \\
\text { BEVs for recharging (CNY) }\end{array}$ & $P_{\mathrm{SUB}}$ & $\begin{array}{l}\text { Active power supplied from the } \\
\text { distribution substation }(\mathrm{kW})\end{array}$ \\
\hline$h$ & FCS number & $Q_{\mathrm{SUB}}$ & $\begin{array}{l}\text { Reactive power supplied from the } \\
\text { distribution substation (kVar) }\end{array}$ \\
\hline$I N V_{h}$ & $\begin{array}{l}\text { Investment cost of the } h^{t h} \mathrm{FCS} \\
(\mathrm{CNY})\end{array}$ & $P_{\mathrm{SUB}}^{\max }$ & $\begin{array}{l}\text { Permitted maximum active power supplied } \\
\text { from the distribution substation }(\mathrm{kW})\end{array}$ \\
\hline$i_{\mathrm{r}}$ & Interest rate (\%) & $Q_{\mathrm{SUB}}^{\max }$ & $\begin{array}{l}\text { Permitted maximum reactive power } \\
\text { supplied from the distribution substation } \\
(\mathrm{kVar})\end{array}$ \\
\hline$i_{\mathrm{p}}$ & Investment period (yr) & $k W h_{\mathrm{EV}}$ & Battery capacity or size of an BEV (kWh) \\
\hline$\varsigma$ & Conversion coefficient & $V_{i}$ & $\begin{array}{l}\text { Voltage magnitude at the } i^{\text {th }} \text { bus of the } \\
\text { power distribution system }(\mathrm{pu})\end{array}$ \\
\hline$\chi$ & Road twist coefficient & $N_{B}$ & Number of buses in the distribution system \\
\hline$\eta$ & $\begin{array}{l}\text { Smooth traffic coefficient of the } \\
\text { road }\end{array}$ & $S_{j}$ & Apparent power flow in the $j^{\text {th }}$ line (MVA) \\
\hline$\delta$ & $\begin{array}{l}\text { Travelling cost rate of an BEV } \\
(\mathrm{CNY} / \mathrm{km})\end{array}$ & $S_{j}^{\text {rated }}$ & $\begin{array}{l}\text { Rated apparent power flow in the } j^{\text {th }} \text { line } \\
\text { (MVA) }\end{array}$ \\
\hline 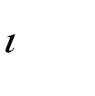 & $\begin{array}{l}\text { Annual recharging frequency } \\
\text { (times/yr) }\end{array}$ & $e f f_{\mathrm{FCS}}$ & Efficiency of FCS \\
\hline$\psi$ & Turnaround coefficient & $P F_{\mathrm{FCS}}$ & Power factor of FCS \\
\hline$G_{p h}$ & 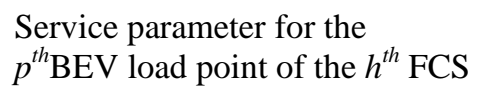 & $\alpha$ & $\begin{array}{l}\text { Relative influence of the pheromone trail } \\
\text { information }\end{array}$ \\
\hline$D_{p h}$ & $\begin{array}{l}\text { Distance between the } p^{\text {th }} \mathrm{BEV} \\
\text { load point and the } h^{\text {th }} \mathrm{FCS} \\
\text { (meter) }\end{array}$ & $\beta$ & Relative influence of heuristic information \\
\hline$n l$ & $\begin{array}{l}\text { Number of BEV load points in } \\
\text { the residential area }\end{array}$ & $\eta_{h i}$ & $\begin{array}{l}\text { Heuristic function of the } h^{\text {th }} \text { station at the } \\
i^{\text {th }} \text { bus }\end{array}$ \\
\hline$T_{\text {alleV }}$ & $\begin{array}{l}\text { Total travelling time for } \\
\text { recharging of all BEVs (hr) }\end{array}$ & $\tau_{h i}$ & Trail intensity of the $h^{\text {th }}$ station at the $i^{\text {th }}$ bus \\
\hline$S_{\mathrm{EV}}^{\mathrm{av}}$ & $\begin{array}{l}\text { Average speed of all BEVs } \\
(\mathrm{km} / \mathrm{hour})\end{array}$ & $O b j_{h i}$ & $\begin{array}{l}\text { Objective function of the } h^{\text {th }} \text { station at the } \\
i^{\text {th }} \text { bus }\end{array}$ \\
\hline$P_{\mathrm{Lj}}$ & $\begin{array}{l}\text { Active power loss at the } j^{\text {th }} \text { line } \\
(\mathrm{kW})\end{array}$ & $\rho$ & Pheromone evaporation coefficient \\
\hline$Q_{\mathrm{L} j}$ & $\begin{array}{l}\text { Reactive power loss at the } j^{\text {th }} \\
\text { line ( } k \text { Var) }\end{array}$ & $O b j^{\max }$ & Maximum objective functions \\
\hline$P_{\mathrm{D} i}$ & $\begin{array}{l}\text { Active power demand at the } i^{\text {th }} \\
\text { bus }(\mathrm{kW})\end{array}$ & $O b j^{\text {best }}$ & Objective function of the best solution \\
\hline$Q_{\mathrm{D} i}$ & $\begin{array}{l}\text { Reactive power demand at the } \\
i^{\text {th }} \text { bus (kVar) }\end{array}$ & $c p u t_{\text {limit }}$ & CPU time limit in computation \\
\hline
\end{tabular}

\section{INTRODUCTION}

Battery electric vehicles (BEVs) are driven by an electric motor powered by rechargeable battery packs. It is known that they do not emit the pollution produced with the internal combustion engine car (ICEs). BEVs can convert about around $80 \%$ of the electrical energy from electric power source to mechanical power. It shows that the energy efficiency of BEV is higher than ICE. However, BEVs can run about around 150 kilometres before recharging at charging station while ICE can run over 500 kilometres before refuelling [1]. In order to release this problem, charging station for electric vehicle (EV) should be installed sufficiently along the street or service area. 
Fast charging station (FCS) could possibly release the speed issue in charging for BEV but it causes some negatives effect to the power distribution network like real power loss [2]. Thus, the FCS planner must plan to reduce this loss. Moreover, they should consider total cost in traveling from BEV owner house to FCS for recharging a day. The investment and operating cost of FCS should be combined as total cost. The optimal placement of FCS is studied in many research works [2-4]. Total cost of charging station and feeder loss cost of distribution network is combined to be single objective under many constraints and it is solved by the modified primal-dual interior point algorithm [2]. The charging station planning with single objective of the total cost under traffic constraints is solved by genetic algorithm [3]. The primary investment, operation and mobility cost is combined to be single objective for optimization problem solved by program processing [4]. However, the multiobjective optimization of both cost associated with FCS and feeder loss in the power distribution system is not yet developed subject to factors of traffic condition, electric power supply of FCS, power distribution system.

Various multiobjective optimization techniques such as multiobjective ant colony optimization (MOACO) [5], nondominated sort genetic algorithm II (NSGA II) [6], and multiobjective particle swarm optimization (MOPSO) [7] can solve multiobjective problems in electrical system. Also, multiobjective hybrid swarm optimization is developed to solve multiobjective optimization problems [8]. However, MOACO is more successful in searching Pareto optimal front [5]. From these reason, hybridizing bi-swarm intelligence for the multiobjective optimal placement of FCS is proposed in this paper to improve performance and efficient of MOACO with Bees algorithm.

This paper proposes the multiobjective optimal placement of FCS on power distribution system under many constraints of the power distribution system and traffic condition. The multiobjective hybrid ant colony optimization and bees algorithm (MOHACOBA) for the optimal allocation of FCS is proposed to minimize simultaneously both cost associated with FCS and feeder loss of distribution network and compared with other multiobjective optimization. The IEEE-69-test system in Tianjin Development Zone is used to test the proposed approachwith three case studies on fast charging head size. Hypervolume ratio, error ratio, spread and epsilon indicator are brought to find performance of MOPSO, NSGA II, MOACO and MOHACOBA. Numerical results and conclusion is presented in last section.

\section{Problem Formulation}

\section{A. Location Graph of FCS Planning on Power Distribution System}

A Tianjin Development Zone of about 10.5 square kilometres as residential area with 3,140 electric vehicles and the location of BEV load points can be found in reference [3]. A FCS can be constructedat bus of IEEE-69bus system in Tianjin Development Zone and its system data of bus and branch can be found in reference [9]. The backward-forward sweep distribution power flow is used to calculate the system operating condition of the systems [10]. In this paper, BEVs use a rapid recharged battery and FCS is constructed as 3-phase with many dc fast charging head. One bus of the IEEE-69-bus has to be chosen from a set of bus numbers in order to install a station of FCS.

\section{B. Mathematic Model of the FCS Planning on Power Distribution System} follow.

The mathematic model of the FCS planning comprises two objective functions under many constraints as

\section{Objective Functions:}

1) The total cost associated with FCS: The total cost associated with FCS in the residential area can be expressed as follows.

$$
\text { Cost }=C_{\mathrm{NV}}+C_{\mathrm{O \& M}}+C_{\mathrm{TRV}}
$$

i) Initial investment cost: Initial investment cost of FCSs is formulated as uniform series capital recovery cost or annual payment for recovery [6] as following equation.

$$
C_{\mathrm{NV}}=\sum_{h=1}^{n_{\mathrm{rCS}}} I N V_{h}\left(\frac{i_{\mathrm{r}}\left(1+i_{\mathrm{r}}\right)^{i_{\mathrm{p}}}}{\left(1+i_{\mathrm{r}}\right)^{i_{\mathrm{p}}}-1}\right)
$$

Where $I N V_{h}$ includes cost of all devices and land cost for constructing a FCS.

ii) Annual operating cost: Operating and maintenance cost of a FCS includes maintenance costs, material costs, staffs' salary, power consumption cost of electric device in a FCS and other operational costs as follows.

$$
C_{\mathrm{O \& M}}=\varsigma \sum_{h=1}^{n_{\mathrm{FCS}}} I N V_{h}
$$

iii) Annual travelling cost of all BEVs in recharging at FCS: Annual travelling cost of BEVs in recharging at FCS is the total travelling cost of all BEVs that drives from BEV load point to FCS to recharge the battery calculated each year. 


$$
C_{\mathrm{TRV}}=\chi \eta \iota \psi \delta \sum_{p=1}^{n l} \sum_{h=1}^{n_{\mathrm{FCS}}} G_{p h} D_{p h}
$$

Where $G_{p h}$ is service parameter of the $p^{\text {th }}$ FCS whetherthe BEV load point selects $h^{\text {th }}$ FCS as a candidate station.

$$
G_{p h}= \begin{cases}1 & \text { If } D_{p h} \leq D^{\max } \\ 0 & \text { otherwise }\end{cases}
$$

Total travelling time $\left(T_{\text {allEv }}\right)$ for recharging of all BEVs is shown as following equation.

$$
T_{\text {allEV }}=\sum_{p=1}^{n l} \sum_{h=1}^{n_{\mathrm{ECS}}} \frac{n_{\mathrm{EV} p} G_{p h} D_{p h}}{S_{\mathrm{EV}}}
$$

2) The total real power loss in the feeder of the power distribution: The total real power loss in the feeder of the power distribution system is formulated as follows.

$$
\text { Loss }=\sum_{i=1}^{N_{\mathrm{S}}} P_{\mathrm{L} i}
$$

Constraints:The constraints include the equality and inequality of electric power flow of the power distribution, power supply constraints of FCS, power distribution system and traffic constraints as follows.

1) Active and reactive power flow balance equation as follows:

$$
\begin{gathered}
P_{\mathrm{SUB}}=\sum_{i=1}^{N_{B}} P_{\mathrm{D} i}+\sum_{i=1}^{N_{\mathrm{B}}} P_{\mathrm{FCS} i}^{\text {input }}+\sum_{j=1}^{N_{\mathrm{S}}} P_{\mathrm{L} j} \\
Q_{\mathrm{SUB}}=\sum_{i=1}^{N_{B}} Q_{\mathrm{D} i}+\sum_{i=1}^{N_{B}} Q_{\mathrm{FCS} i}^{\text {input }}+\sum_{j=1}^{N_{\mathrm{S}}} Q_{\mathrm{L} j} \\
S_{\mathrm{FCS} i}^{\text {input }}=\frac{P_{\mathrm{FS} i}^{\text {output }}}{\text { eff }}=\frac{q_{\mathrm{HCS}} P F_{\mathrm{FCS}}^{\text {output }}}{e f f_{\mathrm{FCS}} P F_{\mathrm{FCS}}} \\
Q_{\mathrm{FCS} i}^{\text {input }}=\sqrt{\left(S_{\mathrm{FCS} i}^{\text {input }}\right)^{2}-\left(P_{\mathrm{FCSi}}^{\text {input }}\right)^{2}}
\end{gathered}
$$

2) Constraint of daily power supplying of FCSs for all BEVs: Electric power consumption of all BEVs which select to charge its battery at the FCS once per a day must be less than daily power supplying of the FCS as follows.

$$
\begin{aligned}
& P_{\mathrm{H}}^{\text {output }} t_{\mathrm{CHG}} \sum_{p=1}^{n l} n_{\mathrm{EV} p} g_{p h} \leq P_{\mathrm{FCSh}}^{\text {output }} t_{\mathrm{S}} l_{\mathrm{F}} \\
& , h=\left(1,2, \ldots n_{\mathrm{FCS}}\right)
\end{aligned}
$$

3) System quality constraint of power distribution network: System quality constraint is defined as voltage limit and voltage deviation of distribution network due to the connection of the FCSs. The constraints of voltage magnitudes of all buses on the distribution network must be within acceptable range and can be written as.

$$
V_{i}^{\min } \leq V_{i} \leq V_{i}^{\max }, i \in N_{B}
$$

The summation of voltage deviation is expressed as follows.

$$
\text { V.D. }=\sum_{i=1}^{N_{B}}\left|1.05-V_{i}\right|
$$

4) Security constraint of distribution system: Security constraints are of feeder line loading limit and substation capacity limit.

$$
\begin{gathered}
S_{\mathrm{lj}} \leq S_{\mathrm{lj}}^{\max }, j \in N_{S} \\
P_{\mathrm{SUB}} \leq P_{\mathrm{SUB}}^{\max } \\
Q_{\mathrm{SUB}} \leq Q_{\mathrm{SUB}}^{\max }
\end{gathered}
$$

5) Constraints of the service radius of FCS: The service radius of FCS must be within the maximum limit of distance as follows.

$$
D_{p h} \leq D^{\max }
$$


6) Constraints of distance between two adjacent FCSs: The distance between two adjacent FCSs must be within the minimum and maximum limit.

$$
D_{\mathrm{FCS}}^{\min } \leq D_{\mathrm{FCS}} \leq D_{\mathrm{FCS}}^{\max }
$$

7) Constraints of service number of FCS: The summation of service parameters of all FCSs must be more than or equal to the number of BEV load points as follows.

$$
\sum_{p=1}^{n l} \sum_{h=1}^{n_{\mathrm{FCS}}} G_{p h} \geq n l
$$

\section{III.MultiobJective Hybrid Ant Colony Optimization And BeEs Algorithm For Solving}

\section{PROBLEM}

A) Multiobjective Optimization Principle

A general multiobjective optimization principle is expressed as follows;

$$
\begin{aligned}
& \operatorname{Min} F(x)=\left(f_{1}(x), f_{2}(x), \ldots . ., f_{N}(x)\right) \\
& \text { subject to } x \in S, x=\left(x_{1}, x_{2}, . ., x_{n}\right)^{T}
\end{aligned}
$$

Where $\left(f_{1}(x), f_{2}(x), \ldots . ., f_{N}(x)\right)$ are the $N$ objectives functions, $\left(x_{1}, x_{2}, . ., x_{n}\right)$ are the $n$ optimization parameters and $S \in R^{n}$ is the solution of problem. Objective vectors, $\{F(x), x \in S\}$, there is no unique solution to this problem. Thus, the concept of Pareto-optimalitymust be used to characterize the objectives.

Definition 1. For a problem having more than one objective function, any two solutions and can have one of two possibilities, one dominates the other or none dominates the other. Asolution $x^{1}$ is said to dominate the other solution $x^{2}$ if both the following conditions are true

1. The solution $x^{1}$ is on worse )the operator $\prec$ denotes worse)than $x^{2}$ in all objectives, or $f_{i}\left(x^{1}\right) \prec f_{i}\left(x^{2}\right)$ for all $i=\{1,2, \ldots, N\}$ objectives.

2. The solution $x^{1}$ is strictly better (the operator $\succ$ denotes better) than $x^{2}$ in at least one objective or $f_{i}\left(x^{1}\right) \succ f_{i}\left(x^{2}\right)$ for at least one $i \in\{1,2, \ldots, N\}$.

If any of the above conditions is violated, the solution $x^{1}$ does not dominate the solution $x^{2}$.

Definition 2. $x^{*}$ is said to be a Pareto optimal solution of multiobjective optimization problem if there exists no other feasible $x$ such that $f_{i}(x) \leq f_{i}\left(x^{*}\right)$ for all $i=\{1,2, \ldots, N\}$ and $f_{j}(x)<f_{j}\left(x^{*}\right)$ for at least one objective function $f_{j}$.

\section{B) Principle of Ant Colony Optimization}

Ant colony optimization (ACO)is motivated by the collective behavior of a real ant colony in nature.

Ant colony optimization is a probabilistic technique and an iterative algorithm which can find best paths in optimization problem designed in pattern of graph. While an ant walk on the path, it will drop pheromone on path. Consequently, accumulated pheromone on the path will continually guide the ants in walking and the path which has many pheromones can be the candidate of best path in current iteration of computation. Each ant will walk until finishing its tour and the best path will be acquired from these mechanisms at last iteration.

\section{C) Principle of Bees algorithm}

Bees algorithm (BA) is an optimization technique motivated by the natural forging behaviour of honeybees. The process of algorithm can be described as follows. Scout bees initially find the food source. They will return to the hive and be raised as an employed forager. Recruited employed foragers will follow an employed forager who memorizes the location of the food source. A number of recruited employed foragers of each food source will depend on the importance of a food source. They will exploit the nectar around neighbourhood area of the food source. After the employed foraging food source, bee loads a portion of nectar from the food source, and then returns to the hive. Moreover, bees will abandon food source that has little nectar. Those bees become new scout bees to search new food source. BA uses these mechanisms in searching optimal solution. 
D) Multiobjective Hybrid Ant Colony Optimization with Bees Algorithm for Solving FCS placement The computation flow of the proposed MOHACOBA algorithm is described as follows.

\section{Step 0:Initialization, the process of this step is the following;}

- $\quad$ Read system data and set initial parameter of MOHACOBA

- Start iteration;

- Initial trail intensity on route is set as $\tau_{h i}(0)=1$ and initial probability distribution on the route is set as $p_{h i}(0)=1$.

- Calculating two heuristic functions which are defined as visibilities of objective function of the $h^{\text {th }}$ station at $i^{\text {th }}$ the bus can be expressed as follow.

$$
\begin{gathered}
\eta_{h i}^{1}=\frac{1}{\operatorname{Cost}_{h i}} \\
\eta_{h i}^{2}=\frac{1}{\operatorname{LosS}_{h i}}
\end{gathered}
$$

Step 1:State transition rule for constructing ant solution;

Update iteration; $t=t+1$

The state transition rule guiding the ant $k$ walking, an ant of the $h^{\text {th }}$ station chooses bus $i$ by applying the pseudo-random proportion rule as given in following equation.

$$
i= \begin{cases}\arg \max _{i \in N_{\mathrm{B}}}\left(\tau_{h i}(t)\right)^{\alpha}\left(\eta_{h i}^{1}(t)\right)^{\lambda_{h 1} \beta}\left(\eta_{h i}^{2}(t)\right)^{\lambda_{h 2} \beta} \text { if } q \leq q 0 \\ \hat{i} \quad \text { otherwise }\end{cases}
$$

The parameter $q 0$ can be set from 0 to 1 and $q$ is a random number in a range of $[0,1]$.

Where $\lambda_{h 1}$ and $\lambda_{h 2}$ are computed by using (25) for each station $h$ in order to force the ants to search in difference regions of the Pareto front $h \in\left\{1,2, . ., n_{\mathrm{FCU}}\right\}$.

$$
\begin{aligned}
& \lambda_{h 1}=\bmod \left(h / n_{\mathrm{FCS}}, 1\right) \\
& \lambda_{h 2}=\bmod \left(h / n_{\mathrm{FCS}}+1,1\right)
\end{aligned}
$$

For $\left(h=1,2, \ldots, n_{\mathrm{FCU}}\right)$ and $\left(\hat{i}=1,2, \ldots, N_{\mathrm{B}}\right), \hat{i}$ is a bus to be selected according to the probability distribution function expressed as follow.

$$
p_{h \hat{i}}(t)=\frac{\left(\tau_{h \hat{i}}(t)\right)^{\alpha}\left(\eta_{h \hat{i}}^{1}(t)\right)^{\lambda_{h 1} \beta}\left(\eta_{h \hat{i}}^{2}(t)\right)^{\lambda_{h 2} \beta}}{\sum_{i=1}^{N_{B}}\left(\tau_{h i}(t)\right)^{\alpha}\left(\eta_{h i}^{1}(t)\right)^{\lambda_{h 1} \beta}\left(\eta_{h i}^{2}(t)\right)^{\lambda_{h 2} \beta}}
$$

Constructing ant population $a_{h k},\left(h=1,2 \ldots, n_{F C U}\right),(k=1, \ldots, m)$, the selection process on the bus $\hat{i}$ of the $h$ station of ant $k$ is based on discrete spinning the roulette wheel between 1 and $N_{B}$ with the probability calculated in (25).

Step 2: Evaluating both objective functions and find Pareto optimal solution;Evaluating both objective functions of feasible solutions and finding the non-dominated solution this iteration by non-dominated sort function:

The non-dominated solution in this iteration will be set as the Pareto optimal solution $\operatorname{Pos}_{p},(p=1,2, . ., n p)$.where $n p$ is the number of the Pareto optimal solutions.

Step 3:Recruit bees around Pareto optimal solution;The process of bees algorithm is used in this step. The bees are recruited from its hive to search around the Pareto front as ${ }_{a n}{ }_{h w p},\left(h=1,2 \ldots ., n_{\mathrm{FCS}}\right),(w=1,2 \ldots ., n b a),(p=1,2 \ldots ., n p)$.

Thenumber of bees around the Pareto solution is $n b a$. The bees are recruited to generate the neighbourhood solution around Pareto solution as following equation and it build new Pareto optimal front.

$$
a n_{h w p}=\operatorname{Pos}_{p}+\operatorname{rand}[0,1] \times n g h \times\left(N_{B}-1\right)
$$


The advantage of this process is to search prudently new Pareto solutions in determined area (controlled by patch sizes $(n g h))$ around the Pareto optimal solution. Consequently, this process can help ant to release from trap of local optimal solution.

Step 4:Combining neighbourhood solution and existing non-dominated solution to find new non-dominated solution;The best compromise solution from new non-dominated solution is acquired by using fuzzy-based mechanism [7].

Step 5:Global updating rule; Global updating is carried out in the best tour from all ants. For $\left(h=1,2, \ldots, n_{\mathrm{FCS}}\right)$ and $\left(i=1,2, \ldots, N_{\mathrm{B}}\right)$, the pheromone update is implemented in following equation.

$$
\Delta \tau_{h i}^{\mathrm{bc}}(t)=\left\{\begin{array}{lc}
k b & \text { if }(h, i) \text { belongs to the best compromise solution at iteration } t \\
0 & \text { otherwise }
\end{array}\right.
$$

Where $k b$ is a positive number.

\section{Step 6: Stopping criteria}

If $c p u_{\text {_time }} \geq$ cput $_{\text {limit }}$ then end; else go to Step 1.

Fig. 1 shows the flowchart of the proposed MOHACOBA algorithm to solve the FCS planning problem.

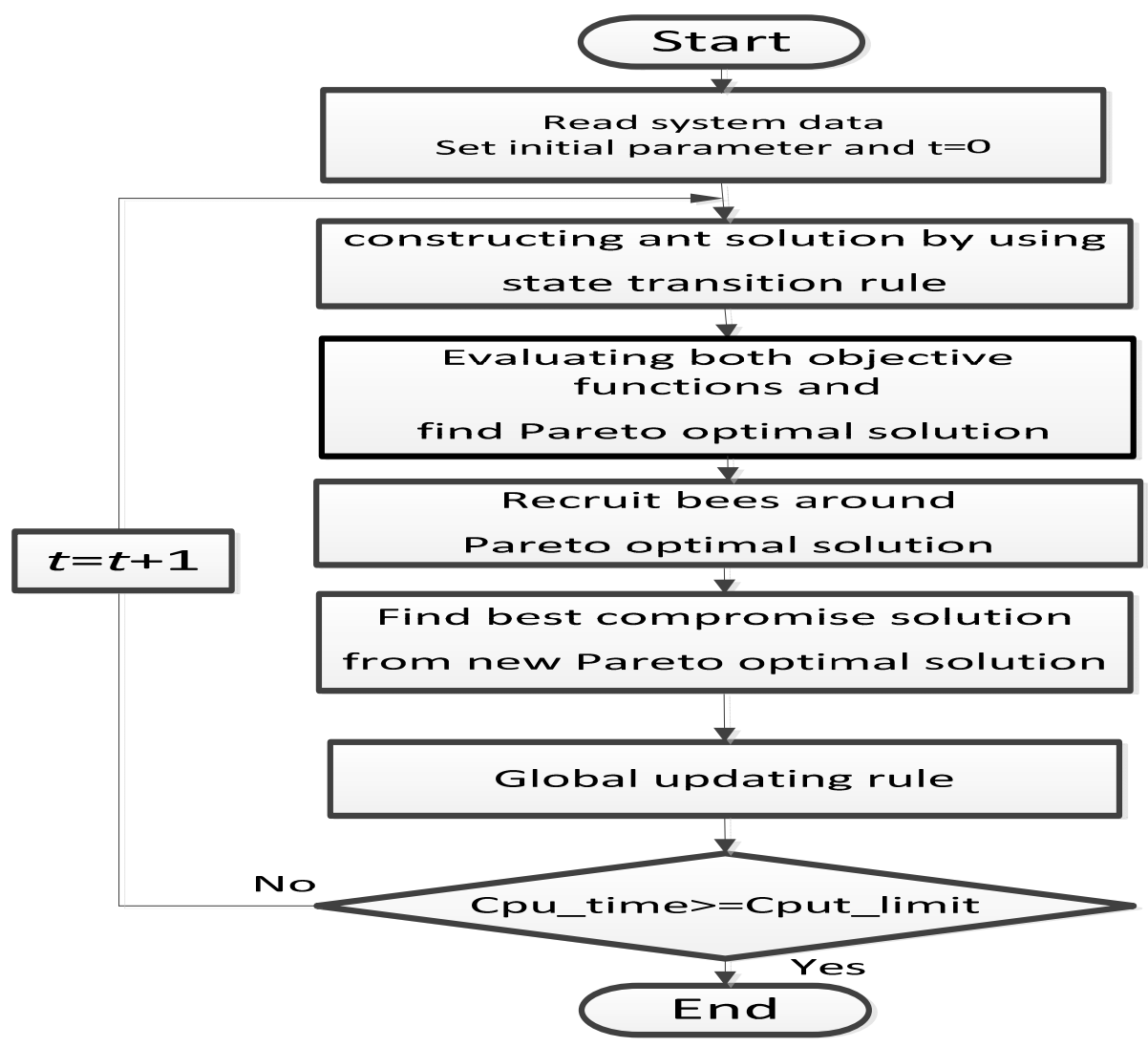

Fig. 1. Flowchart of the proposed MOHACOBA

Merit of the proposed multiobjective algorithm techniquescan be found as follow.

1) It can efficiently overcome the drawback of MOACO that have stagnation behavior in searching.

2) The candidate paths to be selected by the ants has new alternative paths rather than to be fixed because of additional process from bees algorithm. Consequently, the solution will tend to be diverse and various in finding Pareto optimal front.

3) It can find Pareto solutions of multiobjective optimization problems very efficiently. 


\section{E) Quality Measurement of the Pareto Fronts}

Following four metrics are used in this paper to measure the quality of the Pareto-optimal front obtained by various algorithms:

1. Spread: This metric measures the extent of spread or equal spacing of Pareto-optimal solutions along the Pareto-optimal front. As long as the spread is uniform, this metric produces a small value [11].

2. Hypervolume ratio (HV): This metric calculates the normalized volume in the objective space covered by the members of the Pareto optimal front. It is said that whenever a set of Pareto-optimal solution is better than another Pareto set, its hyper volume is higher than the latter one [11].

3. Error ratio: This metric uses the true Pareto front as reference set. Lower values of error ratio are preferable [12].

4. Epsilon indicator: This metric uses the worst-case distance between Pareto front and true Pareto front. The metric is harder to meet, if it have a large gap, it will have poorer metric performance [13].

This paper uses boxplots to present the statistical data of four performance metrics from all methods.

\section{IV.NUMERICAL RESULTS}

Numerical examples of three cases of fast charging head as 43, 60, and $100 \mathrm{~kW}$ following international standards [14] on the IEEE-69-bus test system were performed. The following parameters are set: Set $P_{\mathrm{FCS}}^{\text {output }}=$ $215 \mathrm{~kW}$ and $I N V=215,000 \mathrm{CNY}$, thus $P_{\mathrm{FCS}}^{\text {input }}=221.65 \mathrm{~kW}, Q_{\mathrm{FCS}}^{\text {output }}=45.01 \mathrm{kVar}, S_{\mathrm{FCS}}^{\text {output }}=226.17 \mathrm{kVA} . n_{\mathrm{EV}}$ $=3,140, \quad n l=28, i_{\mathrm{p}}=20, i_{\mathrm{r}}=10 \%, \varsigma=0.12, \chi=1.1, \psi=1.5, \quad \eta=1.1, \quad \delta=1.3, \quad l=180, \quad D^{\max }=1.2, D_{\mathrm{FCS}}^{\min }$ $=0.15, \quad D_{\mathrm{FCS}}^{\max }=3.0, t_{\mathrm{s}}=24, t_{\mathrm{CHG}}=1 / 6, \quad q_{\mathrm{H}}=5, l_{\mathrm{F}}=0.9, t_{\mathrm{S}}=24, \quad e f f_{\mathrm{FCS}}=0.97, \quad P F_{\mathrm{FCS}}=0.98, \quad S_{\mathrm{EV}}^{\mathrm{av}}=50 . n_{\mathrm{FCS}}$ $=6$ and there are 5 fast charging heads per a FCS.

The results were computed by using Pentium core2duo, $2.2 \mathrm{GHz}$ processor, 2GB ram coding by Matlab ${ }^{\circledR}$ programming language. Enumeration is operated to find true Pareto front on the IEEE-69-bus system. 100 trial runs were carried out for all algorithms with $c p u t_{\text {limit }}=250$ seconds. The optimal parameters of MOHACOBA and other optimization techniques for all cases can be obtained from trial and error and is shown in Table I.

TABLE I. Parameters of MOHACOBA and other Optimization Techniques

\begin{tabular}{|c|c|c|c|c|}
\hline Method & Parameter & Case I & Case II & Case III \\
\hline \multirow{4}{*}{ MOPSO } & population & 600 & 600 & 600 \\
\cline { 2 - 5 } & $w_{\max }$ & 0.7 & 0.7 & 0.7 \\
\cline { 2 - 5 } & $w_{\min }$ & 0.2 & 0.2 & 0.2 \\
\cline { 2 - 5 } & $c_{1}$ & 1.4 & 1.4 & 1.4 \\
\cline { 2 - 5 } & $c_{2}$ & 1.4 & 1.4 & 1.4 \\
\hline \multirow{4}{*}{ NSGA II } & population & 300 & 300 & 300 \\
\cline { 2 - 5 } & pc & 0.9 & 0.9 & 0.9 \\
\cline { 2 - 5 } & $n c$ & 20 & 20 & 20 \\
\cline { 2 - 5 } & $n m$ & 20 & 20 & 20 \\
\hline \multirow{4}{*}{ MOACO } & population & 300 & 300 & 300 \\
\cline { 2 - 5 } & alpha & 1.0 & 1.0 & 1.0 \\
\cline { 2 - 5 } & beta & 1.0 & 1.0 & 1.0 \\
\cline { 2 - 5 } & $d_{0}$ & 0.05 & 0.05 & 0.05 \\
\hline & population & 300 & 300 & 300 \\
\cline { 2 - 5 } & alpha & 1.0 & 1.0 & 1.0 \\
\cline { 2 - 5 } & beta & 1.0 & 1.0 & 1.0 \\
\cline { 2 - 5 } & nba & 120 & 120 & 120 \\
\cline { 2 - 5 } & $n g h$ & 0.03 & 0.03 & 0.03 \\
\cline { 2 - 5 } & $d_{0}$ & 0.05 & 0.05 & 0.05 \\
\hline
\end{tabular}




\section{A) Case I: Fast charging head for the FCS is $43 \mathrm{~kW}$}

Set $P_{\mathrm{H}}^{\text {output }}=43 \mathrm{~kW}, P_{\mathrm{FCS}}^{\text {output }}=215 \mathrm{~kW}$ and $I N V=215,000 \mathrm{CNY}$, thus $P_{\mathrm{FCS}}^{\text {input }}=221.65 \mathrm{~kW}, Q_{\mathrm{FCS}}^{\text {output }}=45.01$ kVar and $S_{\mathrm{FCS}}^{\text {output }}=226.17 \mathrm{kVA}$. Fig. 2 show best compromise solution and Pareto optimal front from all methods and true Pareto front. The best compromise solution and location of FCS can be calculated as 286,563.27 CNY and $215.31 \mathrm{~kW}$ at bus [5 19294956 66] and its location on IEEE-69-Bus system can be shown in Fig.3.

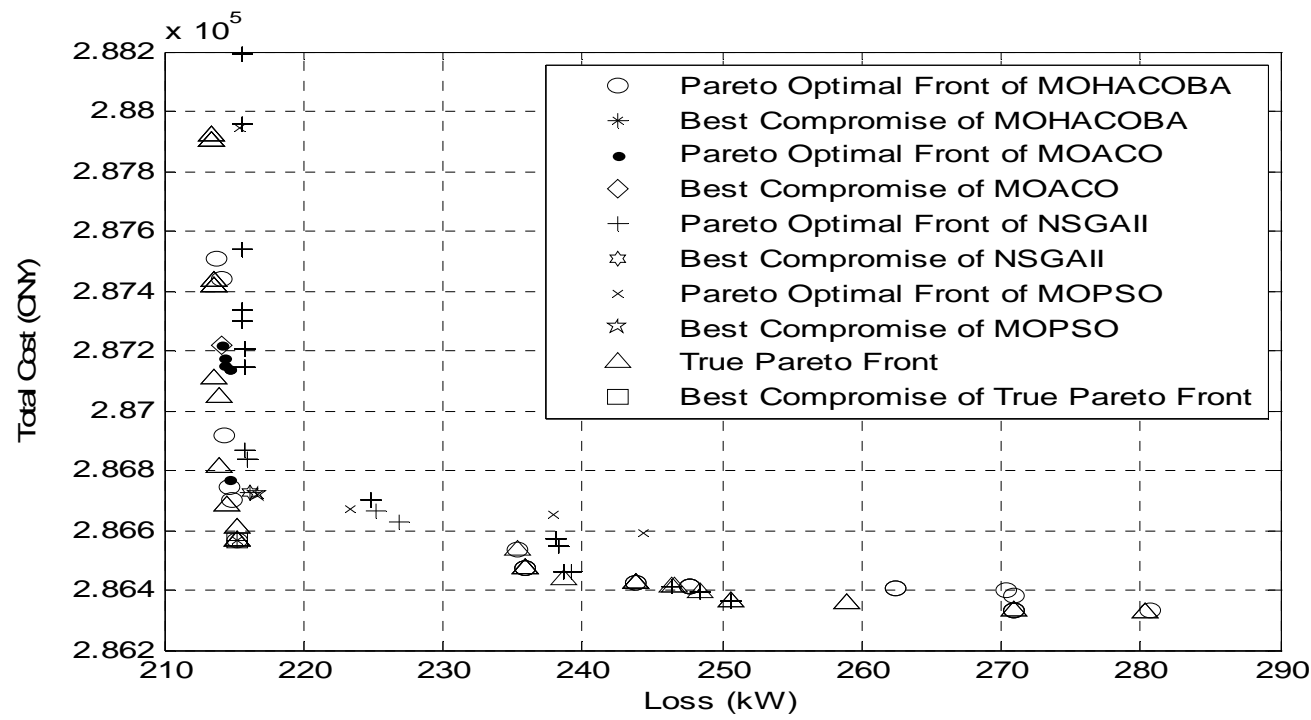

Fig. 2. Best compromise solution and Pareto optimal front in case I

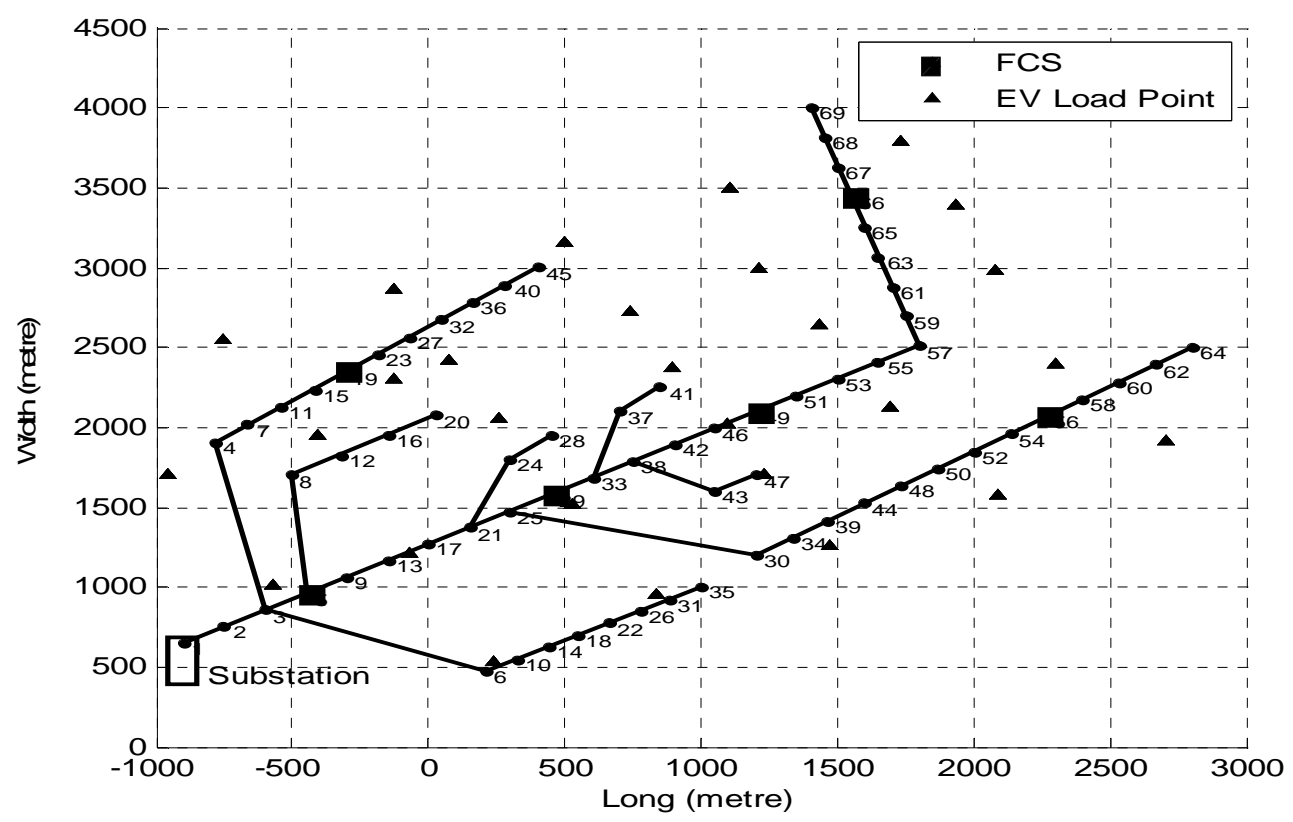

Fig. 3.Best compromise location of FCS on IEEE-69-Bus system in case I

Table 2.show minimum value, best compromise solution, and error ratio of Pareto optimal front from all methods. It can be found that Pareto optimal front of MOHACOBA is closer to true Pareto front. 
TABLE II. minimum value, best compromise solution, and error ratio of Pareto optimal front from all methods

\begin{tabular}{|c|c|c|c|c|c|}
\hline \multirow{2}{*}{ Method } & \multicolumn{2}{|c|}{ Minimum Value } & \multicolumn{2}{|c|}{$\begin{array}{c}\text { Best Compromise } \\
\text { Solution }\end{array}$} & \multirow{2}{*}{$\begin{array}{c}\text { Error } \\
\text { ratio }\end{array}$} \\
\hline & $\begin{array}{l}\text { Minimum } \\
\text { Total Cost }\end{array}$ & $\begin{array}{l}\text { Minimum } \\
\text { Loss }\end{array}$ & Total Cost & Loss & \\
\hline MOPSO & 286588.35 & 215.45 & 286722.75 & 216.64 & 1.00 \\
\hline NSGA II & 286360.33 & 215.56 & 286723.45 & 216.22 & 0.90 \\
\hline MOACO & 286767.86 & 214.06 & 287215.71 & 214.06 & 1.00 \\
\hline МОНАСОВА & 286330.56 & 213.87 & 286563.27 & 215.31 & 0.66 \\
\hline $\begin{array}{l}\text { True Pareto } \\
\text { Front }\end{array}$ & 286328.09 & 213.49 & 286563.27 & 215.31 & 0 \\
\hline Bus & $\begin{array}{c}{\left[\begin{array}{cccc}11 & 13 & 32 & 47 \\
56 & 65\end{array}\right]}\end{array}$ & $\begin{array}{l}{\left[\begin{array}{lll}3 & 13 & 29 \\
36 & 57 & 61\end{array}\right]}\end{array}$ & [5 1929 & $566]$ & \\
\hline
\end{tabular}

B) Case II: Fast charging head for the FCS is $60 \mathrm{~kW}$

Set $P_{\mathrm{H}}^{\text {output }}=60 \mathrm{~kW}, P_{\mathrm{FCS}}^{\text {output }}=300 \mathrm{~kW}$ and $I N V=300,000 \mathrm{RMB}$, thus $P_{\mathrm{FCS}}^{\text {input }}=309.27 \mathrm{~kW}, Q_{\mathrm{FCS}}^{\text {output }}=$ $62.80 \mathrm{kVar}$ and $S_{\mathrm{FCS}}^{\text {output }}=315.59 \mathrm{kVA}$. Fig. 4 show best compromise solution and Pareto optimal front from all methods. The best compromise solution of true Pareto front can be calculated as 397,467.68 CNY and 224.95 kW at bus [5 19294956 66].From Fig.4, MOHACOBA can find the best compromise solution of true Pareto front.

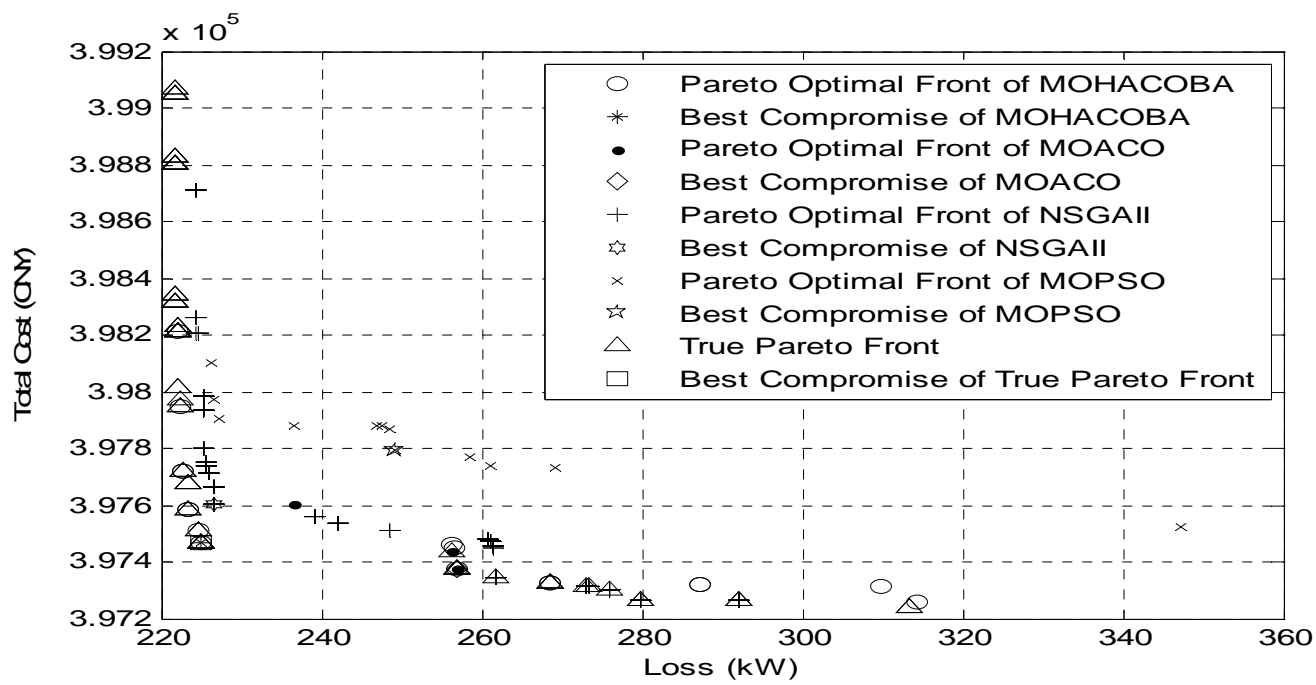

Fig. 4. Best compromise solution and Pareto optimal front in case II

C) Case III: Fast charging head for the FCS is $100 \mathrm{~kW}$

Set $P_{\mathrm{H}}^{\text {output }}=100 \mathrm{~kW}, P_{\mathrm{FCS}}^{\text {output }}=500 \mathrm{~kW}$ and $I N V=500,000 \mathrm{RMB}$, thus $P_{\mathrm{FCS}}^{\text {input }}=515.46 \mathrm{~kW}, Q_{\mathrm{FCS}}^{\text {output }}=104.66$ $\mathrm{kVar}$ and $S_{\mathrm{FCS}}^{\text {oupput }}=525.98 \mathrm{kVA}$. Fig. 5 show best compromise solution and Pareto optimal front from all methods. The best compromise solution of true Pareto front can be calculated as 658,419.22 CNY and $252.23 \mathrm{~kW}$ at bus [5 19294956 66]. From Fig.5, MOHACOBA can find the best compromise solution of true Pareto front. 


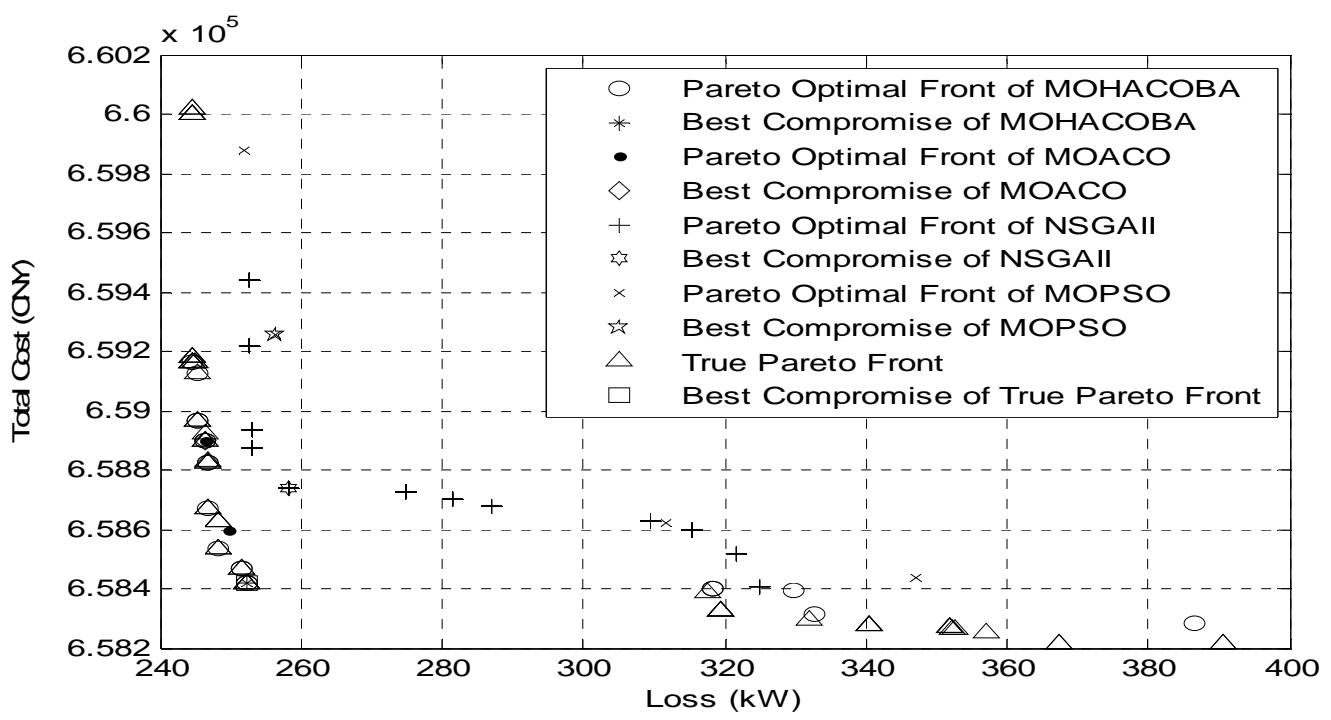

Fig. 5. Best compromise solution and Pareto optimal front in case III

D) The Boxplots of Performance Metric from All Methods for All Cases

Fig. 6show boxplots for the metric of Hypervolume ratio, error ratio, spread and epsilon indicator from all methods. Regarding to Hypervolume ratio in Fig. 6, MOHACOBA has HV value higher than other methods. Moreover, $\mathrm{HV}$ value of MOHACOBA is close to $\mathrm{HV}$ value of true Pareto front (HV ratio = 1). Clearly, error ratio and epsilon indicator of MOHACOBA is lower than other methods. Finally, spread value of MOHACOBA is close to spread value of true Pareto front (Case I $=1.23$, Case II $=1.14$, Case III $=1.15$ ). The results from these metric show that MOHACOBA has performance in finding Pareto optimal front better than other combinational multiobjective optimization for FCS planning problem.
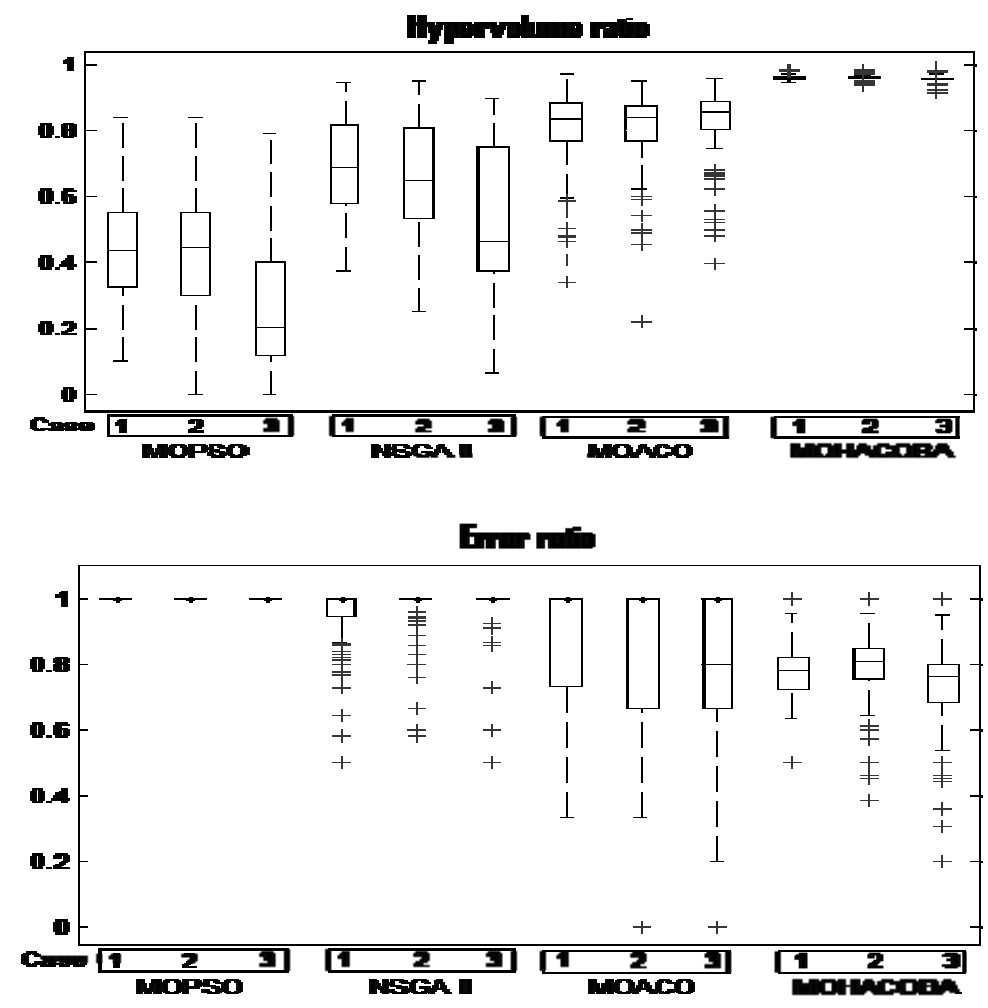


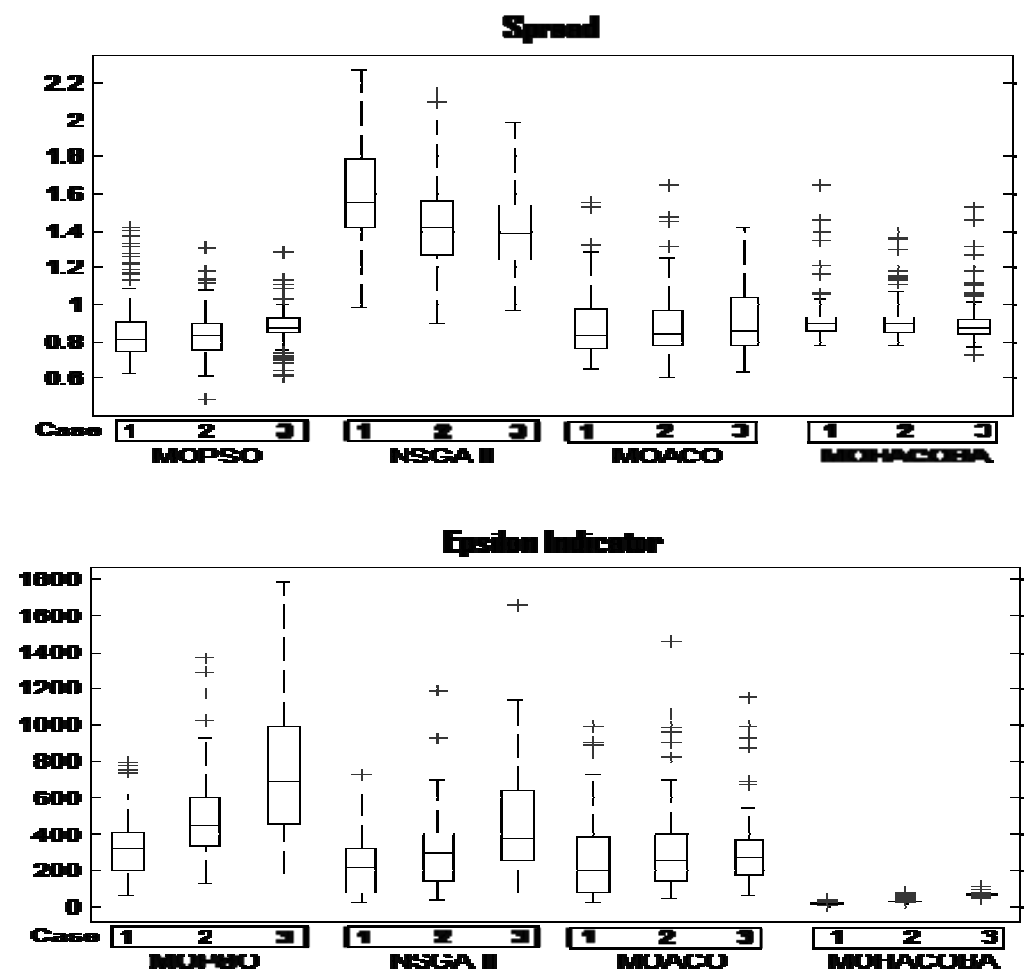

Fig. 6.Boxplots for the metric of Hypervolume ratio, error ratio, spread and epsilon indicator

\section{CONCLUSION}

This paper proposes hybrid ant colony optimization and bees algorithm (MOHACOBA) to minimize simultaneously both cost associated with fast charging station (FCS) and real power loss on distribution network under many constraints of the power distribution system and traffic condition. The IEEE-69-test system is used to test the proposed approach with three case studies on fast charging head size. Hypervolume ratio, error ratio, spread and epsilon indicator is applied for measuring quality of Pareto optimal front of MOPSO, NSGA II, MOACO and MOHACOBA. From the numerical results and boxplots of four metrics, it shows that the performance of MOHACOBA is better than other methods. It can be concluded that MOHACOBA has effectiveness and robustness to find multiobjective optimal placement of FCS on distribution network.

\section{REFERENCES}

[1] J. Wirges, S. Linder and A. Kessler.Modelling the development of a regional charging infrastructure for electric vehicles in time and space, European Journal of Transport and Infrastructure Research, vol. 12, pp. 391-416, 2012

[2] L. Jian, Electric vehicle charging infrastructure assignment and power grid impacts assessment in Beijing, Energy Policy, vol. 51,pp.544-557, 2012

[3] L. Zhipeng, W.Fushuan, and G. Ledwich, Optimal planning of electric-vehicle charging stations in distribution systems, IEEE Transactions on Power Delivery, vol. 28, pp. 102-110,2013

[4] Y. Li,L.Li, J. Yong, Y. Yao, and Z. Li, Layout planning of electrical vehicle charging stations based on genetic algorithm, Lecture Notes in Electrical engineering, vol. 99, pp. 661-668, 2011

[5] J.R. Vilela, ,M.Chica, Ó.Cordón, and S. Damas, A comparative study of multi-objective ant colony optimization algorithms for the Time and Space Assembly line balancing problem, Applied Soft Computing, vol. 13, pp. 4370-4382,2013

[6] M. Basu,Combined heat and power economic emission dispatch using nondominated sorting genetic algorithm-II, International Journal of Electrical Power \& Energy Systems, vol. 53, pp. 135-141,2013

[7] A. Kornelakis, Multiobjective particle swarm optimization for the optimal design of photovoltaic grid-connected systems, Solar Energy, vol. 84, pp. 2022-2033, 2010

[8] A. A. Mousa, , M.A. El-Shorbagy, and W. F. Abd-El-Wahed, , Local search based hybrid particle swarm optimization algorithm for multiobjective optimization, Swarm and Evolutionary Computation, vol. 3, pp. 1-14, 2012

[9] P. Phonrattanasak, and N. Leeprechanon, Optimal placement of EV fast charging stations considering the impact on electrical distribution and traffic condition, Proc. IEEE Green Energy for Sustainable Development (ICUE2014), pp. 1-6,2014

[10] E. Bompard, E.Carpaneto, G.Chicco, and R. Napoli, Convergence of the backward/forward sweep method for the load-flow analysis of radial distribution systems, International Journal of Electrical Power \& Energy Systems, vol. 22, pp. 521-530,2000

[11] A.I. Selvakumar. Civilized swarm optimization for multiobjective short-term hydrothermal scheduling, International Journal of Electrical Power \& Energy Systems, vol. 51, pp. 178-189, 2013

[12] S.J. Tsai, T.Y. Sun, C.C. Liu, S.T. Hsieh, W.C. Wu and S.Y. Chiu.An improved multi-objective particle swarm optimizer for multiobjective problems, Expert Systems with Applications, vol. 37, pp. 5872-5886, 2010

[13] J.R. Vilela, M. Chica, Ó. Cordón and S. Damas.A comparative study of Multi-Objective Ant Colony Optimization algorithms for the Time and Space Assembly Line Balancing Problem, Applied Soft Computing, vol. 13, pp. 4370-4382, 2013

[14] http://www.e-mobile.ch/pdf/2011/20110922_ACEA_Position_Paper_on_EVs_standardisation.pdf 